\title{
POLÍTICA E CIDADANIA: DESAFIOS DA PRÁTICA EDUCATIVA
}

\author{
POLICY AND CITIZENSHIP: CHALLENGES OF \\ EDUCATIONAL PRACTICE
}

\author{
Daniele Dtizel Mattioli* \\ Rita de Cássia da Silva Oliveira ${ }^{* *}$
}

\begin{abstract}
RESUMO
O presente trabalho tem como objeto refletir acerca da presença do senso político nos alunos, para compreender como isso é desenvolvido nas escolas. Inicialmente, apresentamos uma reflexão sobre o papel da educação como um ato político, capaz de formar homens e mulheres que atuem na transformação social, salientando o papel do professor como aquele que instiga seus alunos, proporcionando a eles condições de tornar-se cidadãos efetivos. No segundo momento, abordamos a sala de aula como microcosmo político; e, discutindo a ideia de Estado democrático de direito, procuramos pontuar a importância de tratar nossos alunos como cidadãos.
\end{abstract}

Palavras-Chave: Educação. Senso político. Cidadania.

\begin{abstract}
The present work has as objective to reflect on the presence of political sense in students in order to understand how this work is developed in schools. Initially the paper presents a reflection on the role of education as a political act, capable of forming men who work in social change, stressing the role of the teacher as one who instigates the students giving them conditions to become effective citizens. In the second step, we approach the classroom as a microcosm political and discussing the idea of a democratic state, we emphasize the importance of treating our students as citizens.
\end{abstract}

Keywords: Education. Political sense. Citizenship.

\footnotetext{
" Mestre em Educação pela UEPG. Professora da Rede Estadual de Educação do Paraná. Professora da FASF - Faculdade Sagrada Família. Professora da FATEB - Faculdade de Telêmaco Borba.

${ }^{*}$ Doutora em Educação. Universidade Estadual de Ponta Grossa. Professora do Mestrado e Doutorado em Educação na UEPG. Professora Produtividade pelo CNPQ.
} 


\section{Introdução}

Refletir sobre o trabalho desenvolvido nas escolas, o que se ensina e o como se ensina exige um olhar crítico sobre a prática escolar cotidiana, que não está isolada dos acontecimentos sociais, mas, sim, diretamente vinculada a eles.

Para que não haja confusão entre informação e conhecimento deve o professor estar apto a trabalhar com essa relação, interrogando o passado a partir de questões que nos inquietam no presente.

O presente estudo teve como objeto investigar a presença do senso político nos alunos, compreendido aqui como a capacidade de interpretar e intervir no mundo que o cerca. Assim sendo, constituíam-se objetivos da pesquisa:

- compreender a sala de aula como espaço político, que pode possibilitar ao educando perceber-se como agente histórico capaz de interferir na realidade;

- caracterizar a sala de aula como microcosmo político, apresentando esse espaço como possível, onde os alunos possam experimentar situações que o levem a reconhecer-se como cidadão.

Diante do exposto, a questão colocada é a seguinte: de que maneira o trabalho desenvolvido pelo professor contribui para que seus alunos se reconheçam como cidadãos que compreendem o valor do ser político, e que venham a buscar participação na transformação de seu mundo?

Reconhecemos a profundidade da tarefa de formar alunos críticos, trabalho este que demanda tempo e dedicação da escola como um todo, aliada à convicção de que, sendo a educação um processo constantemente desafiado por um mundo em transformação, torna ainda mais complexa a ação educativa, que busca o pleno desenvolvimento do educando e o seu preparo para o exercício da cidadania. Considerando os objetivos e a questão anteriormente descrita, realizamos este trabalho a partir do entendimento de que, sendo o professor um agente político (mesmo que este assim não se considere), sua prática deve instigar, de acordo com Bezerra (2003, p. 47) o "aprimoramento de atitudes e valores imprescindíveis para o exercício pleno da cidadania". Acreditamos que trabalhos que enfatizam o posicionamento, a defesa de ideias e ideais influenciem nossos educandos, tornando-os, se possível, cidadãos éticos.

O presente trabalho se desenvolveu sob a forma de um estudo exploratório, com a realização de um estudo teórico sobre o tema, baseado na realização de pesquisa bibliográfica, feita em material já elaborado, constituído principalmente de livros e artigos científicos (Moreira, 2008, p. 74).

A pesquisa exploratória é considerada aqui nos moldes em que Gil (1994, p. 44) a entende: "sua principal finalidade é desenvolver, esclarecer e modificar conceitos e ideias, com vistas a formulação de problemas mais precisos ou hipóteses pesquisáveis para estudos posteriores". O caminho para este trabalho é o da utilização de levantamento sobre o tema delimitado por esta pesquisa.

Ao analisar a sala de aula como espaço político destacamos o papel da educação como um ato político, capaz de formar mulheres e homens que acreditem no ser humano e se posicionem diante das situações com condições de intervir no curso da história. Salientamos a importância da postura do professor como aquele que instiga, provoca e proporciona meios para que seu aluno aprenda a ser cidadão.

Sob a perspectiva da sala de aula como microcosmo político - democracia e cidadania - , discutimos a organização política do Brasil como Estado democrático de direito e o papel da escola em educar seus alunos para esta sociedade.

\section{A sala de aula como espaço político}

A sala de aula é compreendida, por esta pesquisa, como uma microssociedade na qual se percebem e se constroem relações inerentes à vida social, tomando como foco a democracia e a cidadania.

Uma importante função da educação é trabalhar os impulsos individualistas a fim de preparar para a vida em sociedade. A sociedade atual exige uma educação planetária que conceba a heterogeneidade ao reconhecer as particularidades dos grupos e das culturas, seus valores, interesses e identidades, de forma que o reconhecimento das diferenças não venha a fundamentar relações de dominação.

O cotidiano da sala de aula, bem como a vida do educando fora dela, são permeados por momentos de escolha, nos quais o estudante realiza opções de acordo com seus valores e pela 
maneira como interpreta os acontecimentos. Cada posicionamento, seja ele de ação ou omissão, configura uma atitude de cunho político. Partindo dessa ideia, que é justamente da ação ou da omissão, refletimos sobre o exercício da política como atividade praticamente inerente ao ser humano, não devendo, portanto, caracterizar a prática dos homens céticos, uma vez que "à atividade política caberia privilegiar o estudo e a transformação das condições objetivas na sociedade que permitissem renovála estruturalmente, com novas relações sociais e políticas, de modo a permitir então a plenitude da vida individual" (Maar, 1994, p. 17).

Mas, para que se alcance a plenitude da vida individual - na qual existe a possibilidade de conciliarmos as condições objetivas que visam a realização de metas maiores, relativas a interesses sociais, com as condições subjetivas que valorizam no homem a sua individualidade e a sua especificidade - é necessário que o contexto político da sociedade o permita. Assim, a democracia é por nós entendida como o regime ideal para levar a esse estágio, já que ela é o regime do poder do povo, em que todos são iguais.

A cidadania moderna, tida na ideia de povo como um conjunto, iniciou-se com Rousseau, para quem a cidadania é concebida mais como uma situação de vigilância sobre o poder do que efetiva participação democrática, resultante do contrato social.

Diante dos vários caminhos possíveis para orientar o trabalho, e tendo como eixo a democracia em sala de aula, o professor deve ter muito claro em qual perfil de cidadão está centrando a construção do conhecimento. Nesse sentido, inferimos que as ações desencadeadas na relação professor-aluno não são neutras, isto é, o educando, ao interagir com seu professor, vai estabelecendo uma relação de cumplicidade, que pode ser consciente ou não. Isso significa que o docente tem responsabilidade sobre as ações que desenvolve juntamente com o grupo, pois as mensagens subliminares que os alunos absorvem caracterizam o que os autores chamam de "currículo oculto". É justamente a dimensão inerente ao currículo oculto que denota que a prática pedagógica não é isenta de características que são muito próprias do professor, características estas que expressam seus valores, sua concepção acerca da educação e como esta se relaciona com a disciplina em que trabalha.
Assim, a neutralidade não é compatível com a prática desenvolvida em sala de aula.

A essa ideia acrescenta Freire (2000, p. 15):

Não existe um processo educacional neutro. A educação ou funciona como instrumento usado para facilitar a integração da geração mais jovem na lógica do sistema atual e trazer conformidade à mesma, ou então torna-se a "prática da liberdade" - o meio através do qual homens e mulheres lidam crítica e criativamente com a realidade e descobrem como participar da transformação de seu mundo.

A prática pedagógica obedece a uma proposta curricular, porém devemos ter clara a ideia de que o currículo não está somente comprometido com a transmissão de conhecimentos, uma vez que possui extrema relevância no processo de formação pelo qual nos tornamos o que somos. Segundo Silva (2000, p. 55) "o currículo é um local onde, ativamente, se produzem e se criam significados sociais" que estão vinculados à relações sociais de poder, e ao serem impostos podem ser contestados.

Acreditamos que é nesse propósito que devem se firmar os professores para que seu trabalho venha a oferecer à sociedade cidadãos críticos e capazes de lutar por um mundo democrático e justo. Assim sendo, a sala de aula é um espaço privilegiado, no qual cada aula se realiza como um espetáculo cheio de vida e de sobressaltos, em que uma relação de interlocutores constroem sentidos. É o que nos lembra Schmidt (1997, p. 56). Esse entendimento leva à compreensão de que o local destinado à realização das aulas não pode ser "desperdiçado" como simples ponto de transmissão de informações.

É no contato cotidiano com seus alunos que o professor tem a oportunidade de demonstrar que, como agentes históricos, temos condições de interferir na realidade, se assim o desejarmos.

A dinâmica moderna gerada pela globalização da economia, combinada ao desenvolvimento científico-tecnológico, introduzida em todos os setores sociais pela dinâmica do processo de geração e divulgação de conhecimento afetou o modo como as relações são sentidas, deixando como ferida aberta o modelo educativo ao exigir grande flexibilidade nas áreas de ação humana, abalando reconhecidas verdades e normas que até então conduziam comportamentos individuais e sociais. 
É necessário também que o professor problematize os assuntos, crie um ambiente propício para o desenvolvimento da aula, despertando o interesse dos alunos. Mudanças na apresentação das aulas para os jovens ajudam a dar o primeiro passo na caminhada que leva os alunos a não apenas se interessar pelo conhecimento, mas sentir necessidade de adquiri-lo. Porém, para obter essa resposta dos alunos, o professor precisa sentir-se desafiado, estudar mais e fazer uma autorreflexão. Nesse sentido, Libâneo (2005, p. 17-18) afirma que

práticas pedagógicas implicam necessariamente decisões e ações que envolvem o destino humano das pessoas, requerendo projetos que explicitem direção de sentido da ação educativa e formas explícitas do agir pedagógico. Quem se dispuser ao agir pedagógico estará ciente de que não se pode suprimir da pedagogia o fato de que ela lida com valores, com objetivos políticos, morais, ideológicos.

Como já afirmamos, as relações sociais do mundo contemporâneo sofrem interferência dos sistemas político e econômico e dos avanços tecnológicos que alcançam o campo educacional.

A dificuldade em compreender o outro, em ouvir e aceitar uma opinião, mesmo que conflitante com a nossa, já não faz parte do cotidiano das pessoas. Está cada vez mais fácil saber o que acontece no mundo através da internet, onde as relações pessoais acabam por ocorrer de forma totalmente desligada de responsabilidade, uma vez que em geral não se conhece o interlocutor.

Tamanha é a facilidade e a quantidade de informações disponíveis que as atividades que exigem um esforço maior acabam relegadas a segundo plano. O nível de relacionamento humano torna-se menor a partir do momento em que a sociedade vai fechando suas portas e em que se exalta o "ser sozinho".

Ao propor atividades que possibilitem distintas interpretações, o aluno acabará por identificar-se com determinada linha de pensamento e terá de argumentar o porquê de sua escolha, ao mesmo tempo que deverá ouvir os argumentos dos colegas que entenderam ser mais adequada outra maneira de pensar. É estabelecido então um debate, no qual passarão a conviver pensamentos distintos que, por estar em um mesmo ambiente, deverão encontrar meios para uma convivência harmoniosa.

Nesses momentos, em que precisam apresentar suas ideias e conhecer as de seus colegas, os alunos passam a vivenciar situações que exigem o respeito às diferenças de pensamento.

Concebendo a sala de aula como o espaço favorável à formação de cidadãos críticos, espaço onde o conhecimento vai sendo construído por meio da realização da pesquisa como princípio científico e educativo, Demo (1994, p. 33) afirma que:

Se a educação se diz emancipatória, não poderá prescindir de lançar mãos deste meio. Não corresponderá ao desafio da cidadania moderna, se permanecer na mera transmissão, cópia, reprodução de conhecimento, no puro ensino e na pura aprendizagem, nos treinamentos domesticadores. Onde o aluno é objeto de aprendizagem, copiam-se lacaios, não se fazem cidadãos competentes. Onde o professor apenas ensina, reproduz-se a sucata, não projeto próprio de desenvolvimento.

Através de práticas emancipatórias teremos que a mulher e o homem educados não serão seres passivos e inconsequentes e sim pessoas mais livres, porque dispõem de uma formação mais satisfatória.

Ao sentir-se parte do processo histórico, ao perceber que suas ações fazem diferença, educandos passarão a atuar de maneira mais efetiva na sociedade, trabalhando para a consolidação dos valores humanos, tão desgastados e esquecidos hoje em dia. Observarão a cada dia que não é possível participar de discussões, debates e muito menos realizar transformações sem o conhecimento teórico, que então passará a ser buscado.

É esse o espírito político que se espera desenvolver nos alunos. Que eles sejam capazes de se colocar diante de uma situação e de tomar as decisões necessárias com vistas a seu próprio bem ou o bem do grupo em que estão inseridos. É praticamente indissociável o gosto pela política nos alunos que se fazem sujeitos históricos. Maar (1994, p. 8) esclarece que:

[...] a política surge junto com a própria história, com o dinamismo de uma realidade em constante transformação que continuamente se revela insuficiente e insatisfatória e que não é fruto do acaso, mas resulta da atividade dos próprios homens vivendo em sociedade. Homens que, portanto, têm 
todas as condições de interferir, desafiar e dominar o enredo da história.

Para isso se faz necessário que o professor seja alguém que tenha essa disposição e coragem. Todo aquele que se diz educador democrático "não pode negar-se o dever de, na sua prática docente, reforçar a capacidade crítica do educando, sua curiosidade, sua insubmissão" (Freire, 2002, p. 28). É função da escola mobilizar a comunidade estudantil na busca de mudanças ou, nas palavras de Canivez (1991, p. 61), a "escola desempenha um papel nessa desmobilização. Impõe de fato ao indivíduo uma certa consciência de sua identidade social, de sua dignidade ou de sua indignidade cultural, classificando-lhe os hábitos, os gostos e ideias numa hierarquia", trabalhando assim para a manutenção da ordem e do status quo vigente.

E quando se fala em homem político, remetemos a Demo (2001, p. 17), que o conceitua como "aquele que tem consciência histórica. Sabe dos problemas e busca soluções. Não aceita ser objeto. Quer comandar seu próprio destino". Mais ainda, é aquele que "não se ilude sobre suas limitações; exatamente por causa disso consegue enfrentá-las" (Demo, 2001, p. 18).

No momento em que as aulas oferecerem esse sabor de luta e transformação, deixaremos de sonhar com um mundo mais justo para, enfim, saboreá-lo.

\section{A sala de aula como microcosmo político - democracia e cidadania}

A lógica que orienta esta pesquisa é a de que, sendo um dos objetivos educacionais a formação de cidadãos críticos, que tenham condições de atuar na sociedade com vistas a transformá-la, então isso pode ser ensinado na escola.

Pensando a sala de aula como microcosmo político, encontramos no argumento de Giroux (apud Silva, 2000, p. 54), de que a escola e o currículo devem funcionar como uma "esfera pública democrática", a sustentação para o entendimento que oferecemos da sala de aula. Nesse sentido, esse espaço deve fornecer ao estudante a possibilidade de desenvolver e praticar as habilidades democráticas da discussão e da participação, do questionamento das implicações do senso comum na vida social, sendo então os professores vistos como pessoas ativamente envolvidas nas atividades da crítica e do questionamento, em concordância com a concepção de intelectuais transformadores apresentada por Giroux.

Para que possamos elucidar esse entendimento devemos ter muito claras as concepções de democracia e cidadania aqui trabalhadas. Tentamos encontrar em Bobbio (1997, p. 322-323) uma definição de democracia que nos permitisse delimitar sua compreensão. Contudo, nos deparamos com o problema de a reflexão sobre a democracia (suas características e importância) ter sido reproposta e reformulada em todas as épocas. Convergem na teoria contemporânea da democracia a teoria clássica, segundo a qual a democracia é o governo do povo, de todos os cidadãos, ou seja, aqueles que gozam dos direitos de cidadania; a teoria medieval, que se apoia na soberania popular; e a teoria moderna, conhecida como teoria de Maquiavel, em que a democracia nada mais é que uma forma de república, da qual se origina um intercâmbio entre ideais democráticos e ideais republicanos.

Iremos centrar nossa discussão na tradição republicana moderna, na qual imagens da democracia e da república terminam por confundir-se. A noção de república de Maquiavel, elemento essencial da democracia moderna - pois é a forma de governo em que o poder não está concentrado nas mãos de um só, mas é distribuído por diversos órgãos opõe-se a toda forma de despotismo. Entretanto, será em Rousseau que o ideal republicano e o ideal democrático coincidirão. A doutrina da soberania popular (formação da vontade geral) e o ideal igualitário da ideia republicana contra a desigualdade dos regimes despóticos se fundem, sendo o Estado construído por Rousseau uma democracia que ele prefere chamar de república.

Esta democracia presume a existência de cidadãos, sujeitos formadores de determinado corpo político em suas relações de direito e dever. Onde tais direitos não existam nem estejam garantidos, tem-se o direito de lutar por eles e exigi-los. Muito mais que a presença do cidadão, reconhecido como possuidor de direitos e deveres, se faz indispensável o exercício da cidadania, atitude pela qual os homens tendem a abandonar a passividade e o individualismo para se tornar participantes da "coisa pública”. 
Promover a interação entre política e sociedade na sala de aula, por meio de referências a situações concretas, problematizando-as com os alunos, pode ser instrumento favorável para despertar interesse no tocante à cidadania. O tempo em sala de aula pode contribuir para que os jovens se identifiquem como sujeitos da história, capazes de fazer uma leitura crítica não só dos livros e textos estudados durante as aulas, mas também uma leitura detalhada das relações sociais pelas quais passam.

O desenvolvimento do trabalho em sala de aula deve estar centrado na preocupação de preparar os jovens para o mundo que os aguarda. Nesse sentido, a formação do estudante deve oferecer condições para que ele aprenda a reconhecer os limites de sua atuação na transformação da realidade histórica em que vive.

Esse caráter da educação, na qual se pretende a formação de agentes capazes de transformar experiências em ações concretas, auxiliando ativamente a edificação de uma sociedade digna, deve extrapolar o que ainda hoje se entende por sala de aula. Giroux (1997, p. 66) coloca que "analisada do ponto de vista do estudante, a sala de aula torna-se uma miniatura do local de trabalho, na qual o tempo, o espaço, o conteúdo e a estrutura são fixadas pelos outros".

O saber que o aluno traz para a sala de aula não pode simplesmente ser descartado. O professor precisa auxiliar a classe a lapidar esse conhecimento, transformando-o no cabedal de saberes responsável por tornar os alunos verdadeiramente livres - e a liberdade é compreendida aqui como o direito de expressar opiniões, vê-las debatida entre colegas que podem aprova-la ou rejeitá-la.

Importa lembrar que cabe aos educadores a tarefa de impedir que sua sala de aula trabalhe a serviço da manutenção da ideologia dominante. Libâneo (2011, p. 25) reforça que

[...] à escola caberia assegurar, a todos, em função da formação geral, os saberes públicos que apresentam um valor, independentemente de circunstâncias e interesses particulares; junto a isso, caberia a ela considerar a coexistência das diferenças e a interação entre indivíduos de identidades culturais distintas, incorporando, nas práticas de ensino, as práticas socioculturais.
Saviani (2010, p. 421-422) entende a educação como "ato de produzir, direta e intencionalmente, em cada indivíduo singular, a humanidade que é produzida histórica e coletivamente pelo conjunto dos homens [...] como mediação no seio da prática social global". Desse modo, a ação educativa deve "partir de uma prática em que professor e aluno se encontram igualmente inseridos, ocupando, porém, posições distintas, condição para que travem uma relação fecunda na compreensão e no encaminhamento da solução dos problemas postos pela prática social" (Saviani, 2010, p. 422).

Mesmo quando o educador, por razões diversas, desanima perante o grupo de alunos e acaba por perder a esperança de que a educação é uma das alternativas capazes de promover as mudanças sociais necessárias, que conduzirão a um mundo onde as diferenças sejam respeitadas e os direitos de fato vivenciados, ele não pode abdicar de seu papel de conscientização, satisfazendo-se em transmitir o discurso vazio de luta pela construção de um mundo melhor para as gerações futuras. É preciso lutar por um mundo melhor no presente.

Podemos considerar que o fim último da educação é a formação do cidadão capaz de atuar na sociedade com responsabilidade e ética. É mais do que perceptível que não educamos nossos alunos para nós, muito menos para nossas avaliações e sim para a sociedade - organizada dentro de um modelo que, necessitando ou não de alteração, tem de ser respeitado para que se consiga usufruir da tão aclamada cidadania.

O Brasil é determinado como um Estado democrático de direito no artigo primeiro da Constituição Federal de $1988 .{ }^{1}$ Nada mais justo que para aprender a viver em um estado assim estruturado, as salas de aula também sejam "salas de aula democráticas de direito".

A educação, consagrada como um dos direitos básicos de todo cidadão, em uma sociedade como a nossa segue,

[...] em sua distribuição, no que permite e no que impede, as linhas que estão marcadas pela

\footnotetext{
${ }^{1}$ Constituição da República Federativa do Brasil, 1988. Artigo 1ำ A República Federativa do Brasil, formada pela união indissolúvel dos Estados e Municípios e do Distrito Federal, constitui-se em Estado Democrático de Direito e tem como fundamentos: I - a soberania; II - a cidadania; III - a dignidade da pessoa humana; IV - os valores sociais do trabalho e da livre iniciativa; $\mathrm{V}$ - o pluralismo político.
} 
distância, pelas oposições e lutas sociais. Todo sistema de educação é uma maneira política de manter ou de modificar a apropriação dos discursos, com os saberes e os poderes que eles trazem consigo (Foucault, 2000, p. 44).

Temos nas salas de aula grupos heterogêneos, com histórias individuais distintas, diferentes formas de percepção da realidade e algumas vezes conflitos de interesses entre o grupo. Em função disso, Canivez (1991, p. 33) demonstra que "a escola de fato, institui a cidadania. É ela o lugar em que os indivíduos estão reunidos pela obrigação de viver em comum. A escola institui [...] a coabitação de seres diferentes sob a autoridade de uma mesma regra".

Com base na conferência pronunciada em Porto Alegre pelo dr. Friedrich Müller (2000), onde discutiu-se a questão de "Qual o grau de exclusão social que um sistema democrático, para manter-se como tal, pode aceitar?", passaremos a tratar a questão da democracia.

O sistema democrático deve apresentar-se baseado na soberania e na autodeterminação popular o que implica a participação efetiva no processo de decisão política.

Para visualizar a sala de aula organizada como reflexo da nossa sociedade, será colocada a questão conceitual do Estado de direito indicada por Carré de Malberg (2001, p. 2-3):

Por Estado de Direito se deve entender um Estado que submete-se ele mesmo a um regime de direito. O regime de Estado de Direito implica que a autoridade administrativa está obrigado a respeitar a lei, obrigado a atuar em virtude somente de habilitações legais. Estado de Direito implica que as regras limitadoras que o Estado tenha imposto a si mesmo, no interesse de seus súditos, poderão ser alegadas por estes da mesma maneira que se alega o direito. O regime de Estado de Direito se estabelece no interesse dos cidadãos e tem por fim especial preservá-los e defendê-los contra a arbitrariedade das autoridades estatais.

Transportando o conceito de Estado de direito descrito acima para a escola, teremos a presença do "contrato pedagógico" pensado por Rousseau. Este irá apoiar-se na confiança, uma vez que o educando obedece as ordens de seu educador porque sabe que não lhe é imposto nada que ele mesmo não possa querer. A importância desse acordo pedagógico encontra respaldo na proposta pedagógica ${ }^{2}$ de cada estabelecimento, onde estão registrados os objetivos, as metas, o referencial que deve permear toda a prática educativa desenvolvida na escola. É a proposta pedagógica que congrega os fundamentos que caracterizam (ou que deveriam caracterizar) a ação docente. O objetivo do "contrato pedagógico" é fornecer ao educador uma base sólida, não acabando com a sua autoridade nem com a liberdade do aluno.

É possível visualizar como essa autoridade seria exercida na sala de aula quando a imaginamos sob a forma de uma república. Tal situação é pertinente

[...] porque a aprendizagem da deliberação e da decisão em comum, a aptidão em compreender um outro ponto de vista e a se fazer entender, o hábito de submeter seus desejos às injunções da situação, assim como o de formular projetos em termos aceitáveis por todos supõem uma certa prática. (Canivez, 1991, p. 37).

Esse primeiro contato com a autoridade possui papel decisivo para que, ao saírem da escola, os "cidadãos" formados não sejam submissos nem revoltados perante a autoridade política, reflexos da sua relação primitiva com a autoridade do adulto, nesse caso específico, o professor. Segundo Rousseau, citado por Canivez (1991, p. 36) "a autoridade que se exerce sobre a criança deve ser tão impessoal quanto a autoridade da lei à qual se submete o cidadão".

O paralelo traçado aqui entre sala de aula e Estado é possível porque:

[...] o Estado é [...] fundamentalmente educador: suas leis não são imperativos puramente exteriores ao indivíduo. Também não são simples convenções que permitem a colaboração pacífica e as trocas comerciais. Elas educam a vontade num ou noutro sentido: um Estado justo predispõe seus cidadãos a quererem o sentido da justiça e do direito. (Canivez, 1991, p.56)

Nesse sentido, também se deve-se atentar para a questão de como a liberdade se faz presente nos regimes democráticos. Nota-se qual é o seu sentido no conceito de liberdade em Montesquieu (2004, p. 188):

\footnotetext{
2 A elaboração da proposta pedagógica encontra respaldo no artigo 12 da
} LDB 9.394/96. 
É verdade que nas democracias o povo parece fazer o que quer, mas a liberdade política não consiste de modo algum em fazer o que se quer. Num Estado, ou seja, numa sociedade onde existem leis, a liberdade não pode consistir senão em poder fazer aquilo que se deve querer e em não ser de maneira alguma constrangido a fazer aquilo que não se deve querer. [...] A liberdade é o direito de fazer tudo o que é permitido pelas leis, e se um cidadão pudesse fazer o que elas proíbem, ele não teria mais liberdade, porque os outros cidadãos teriam do mesmo modo esse poder.

Como se pode perceber, a existência de cidadãos é intrínseca ao Estado de direito. Analisando do ponto de vista político, Chaui (1999, p. 117) define o cidadão como o indivíduo situado no tecido das relações sociais como portador de direitos e deveres, relacionando-se com a esfera pública do poder e das leis, mas que hoje pode ser ampliado como o direito de viver decentemente, segundo bem coloca o jornalista Gilberto Dimenstein (1997, p. 8) em seu livro Cidadão de papel. Ao elencar problemas da sociedade brasileira como violência, educação, desemprego, inflação, ele constata que o brasileiro usufrui de uma cidadania aparente, pois possui direitos garantidos no papel. Esses direitos não se fazem presentes no cotidiano das pessoas, o que poderia levar à conclusão de que em nosso país a cidadania também é de papel.

Por outro lado, a cidadania não pode ser entendida como um título que se recebe; a cidadania vai além. Ela exige o senso de uma ligação cívica entre semelhantes ou alguma responsabilidade com o bem-estar cívico, caso contrário não se aplica a um cidadão verdadeiro, apesar de seu status legal.

Em consonância com o entendimento ampliado da cidadania, Gohan (2004, p. 143) apresenta o conceito de participação cidadã,

[...] lastreada num conceito amplo de cidadania, que não se restringe ao direito ao voto mas ao direito à vida do ser humano como um todo. Por detrás dele há um outro conceito, de cultura cidadã, fundado em valores éticos universais, impessoais. A Participação Cidadã funda-se também numa concepção democrática radical que objetiva fortalecer a sociedade civil no sentido de construir ou apontar caminhos para uma nova realidade social, sem desigualdades nem exclusões de qualquer natureza. Busca-se a igualdade mas reconhece-se a diversidade cultural.

No caso brasileiro, embora exista garantia formal, os direitos não são usufruídos por toda a coletividade. Como resultado dessa segregação maciça de uma grande parcela da sociedade brasileira, inexiste a base social para o exercício dos direitos políticos, uma vez que as pessoas "estão por demais ocupadas com a sobrevivência no dia a dia", como bem coloca o professor doutor Friedrich Müller (2000, p. 21). Essa constatação acaba por fragilizar a nossa democracia, que é criação e garantia de direitos; e a sociedade brasileira, polarizada entre a carência e o privilégio, não consegue ser democrática, pois não encontra meios para isso (Chaui, 1999, p. 436).

"A democracia é uma das formas de Estado que, no plano da ética política, não é compatível com a exclusão" (Müller, 2000, p. 22) e somente pode subsistir como democratização em ampliação permanente.

Como dever do Estado, a educação é o espaço ideal para a inserção do jovem no cenário da discussão política, entendida como o modo pelo qual os humanos podem expressar suas diferenças e conflitos sem transformá-los em guerra total, sem uso da força, sem extermínio recíproco. É também o modo pelo qual a sociedade internamente dividida discute, delibera e decide em comum para aprovar ou rejeitar as ações que dizem respeito a todos os seus membros (Chaui, 1999, p. 370).

O conceito de cidadania sofreu uma redefinição, o que ampliou consideravelmente seu raio de compreensão. A partir das colocações de Marshall, citado por Fernandes (1993, p. 270), a cidadania é formada pelo conjunto de direitos civis, direitos políticos e direitos sociais.

A cidadania civil engloba os direitos necessários à liberdade individual e o direito à justiça; a cidadania política envolve o direito à participação, $\mathrm{o}$ exercício do poder político; a cidadania social compreende os direitos a ao menos um mínimo de bem-estar social e econômico, à segurança, à educação e à cultura.

Pela análise sobre o que é o cidadão no Estado democrático de direito, Demo (2001, p. 34) sinaliza a urgência em "despertar para a necessidade de organização política dos interessados [...] reivindicando direitos, não pedindo favores". 


\section{Considerações finais}

Considerando que o objeto deste trabalho foi verificar a presença do senso político nos educandos, e tendo em mente que "a proposta da universalização da educação básica tem como efeito, entre outras coisas, elevar a capacidade política da população de controlar o Estado" e que "para ele a fidelidade do ignorante é preferível à informação crítica" (Demo, 2001, p. 78), abordamos como a política é hoje entendida no espaço da sala de aula.

É de todos conhecida a certeza de que o caminho para o desenvolvimento do país está na luta contra formas de opressão social e econômica e no investimento na educação, que é por excelência uma forma de intervenção no mundo capaz de reproduzir a ideologia dominante ou desmascará-la.

Justamente pelo perigo que oferece àqueles que obtém vantagens com a manutenção da ordem vigente é que à educação são disponibilizados recursos limitados.

Verificando esse saber fundamental, indicado por Paulo Freire (2002, p. 88) — "mudar é difícil, mas é possível" - o educador deve buscar na sua prática, contrariando toda a ordem de condições que possui para desenvolver o trabalho, seu papel na transformação social.

É nesse momento que o professor deve centrar sua atenção na busca de meios eficazes para desenvolver nos alunos habilidades e competências que venham a lhe fornecer subsídios para formá-los cidadãos éticos.

Ao fazer esse recorte, optando por determinadas posturas diante de seus alunos, o professor está sendo político. Posicionamento de grande relevância, principalmente num país como o nosso, redemocratizado nos aspectos formais mas com padrões de desigualdade de fazer inveja aos genocídios clássicos do passado (Karnal, 2003, p. 9).

O Brasil é um Estado democrático de direito, e por isso os cidadãos só assim são declarados quando lhes são reconhecidos alguns direitos fundamentais. No que diz respeito aos

[...] direitos do homem, por mais fundamentais que sejam, são direitos históricos, ou seja, nascidos em certas circunstâncias, caracterizadas por lutas em defesa de novas liberdades contra velhos poderes, e nascidos de modo gradual, não todos de uma vez e nem de uma vez por todas (Bobbio, 1992, p. 5).

Para que o regime democrático seja efetivamente vivenciado, é fundamental que se torne cotidiano, exercido por todos a todo momento. Ao discutirmos qual formação pretendemos que nossos alunos recebam, a prática democrática deve ser uma constante nas salas de aula.

\section{Referências bibliográficas}

BEZERRA, Holien Gonçalves. Ensino de História: conteúdos e conceitos básicos. In:

BITTENCOURT, Circe (Org.). O saber histórico na sala de aula. São Paulo: Contexto, 1997.

BOBBIO, Norberto. A era dos direitos. Rio de Janeiro: Campus, 1992.

BOBBIO, N.; MATTEUCCI, N.; PASQUINO, G. Dicionário de política. 9. ed. Brasília: Editora da Universidade de Brasília, 1997.

BRASIL. Lei $\mathrm{n}^{0} 9394$ de 20/12/96. Estabelece as diretrizes e bases da Educação Nacional. Brasília: Diário Oficial da União, ano CXXXIV, n 248, de 23/12/96.

BRASIL. Constituição Federal Brasileira. Brasília, 1988.

CANIVEZ, Patrice. Educar o cidadão? Campinas: Papirus, 1991.

DEMO, Pedro. Pesquisa e construção de conhecimento: metodologia científica no caminho de Habermas. Rio de Janeiro: Tempo Brasileiro, 1994.

Pobreza política. 6. ed. Campinas: Autores Associados, 2001.

Politicidade da educação e/ou aprendizagem reconstrutiva política. Núcleo de Estudos e Pesquisas em Educação Tecnológica -Centro Tecnológico - Universidade Federal de Santa Catarina, outubro de 1999. Disponível em $<$ www.nepet.ufsc.br>. Acesso em 7 fev.2004, p. 2.

DIMENSTEIN, Gilberto. Cidadão de papel: a infância, a adolescência e os Direitos Humanos no Brasil. 13. ed. São Paulo: Ática, 1997.

FERNANDES, José Ricardo Oria. Educação patrimonial e cidadania: uma proposta alternativa para o ensino de história. In: Revista Brasileira de História. São Paulo, ANPUH/ Marco Zero, vol.13. n 25/26, set.92/ago.93.

FOUCAULT, Michel. A ordem do discurso. 6. ed. São Paulo: Loyola, 2000.

FREIRE, Paulo. Pedagogia do oprimido. 29. ed. Rio de Janeiro, São Paulo: Paz e Terra, 2000. 
Pedagogia da autonomia: saberes necessários à prática educativa. 22. ed. São Paulo: Paz e Terra, 2002.

GIL, Antonio Carlos. Métodos e técnicas de pesquisa social. 4. ed. São Paulo: Atlas, 1994.

GIROUX, H.; PENNA, A. Educação social em sala de aula: a dinâmica do currículo oculto. In: GIROUX, Henry A. Os professores como intelectuais. Porto Alegre: Artes Médicas, 1997.

GOHN, Maria da Glória. Sociedade civil no Brasil: movimentos sociais e ONGs. NÓMADAS (COL), $\mathrm{n}^{\circ} 20$, p. 140-150. Bogotá: Universidad Central, 2004. Disponível em: $\quad<$ http://redalyc.uaemex.mx/src/inicio/ArtPdfRed. jsp?iCve $=105117734013>$. Acesso em: 4ago.2012.

KARNAL, Leandro (Org.). História na sala de aula: conceitos, práticas e propostas. São Paulo: Contexto, 2003.

LIBÂNEO, José Carlos. As teorias pedagógicas modernas revisitadas pelo debate contemporâneo na educação. In: LIBÂNEO, José Carlos; SANTOS, Akiko(Orgs.). Educação na era do conhecimento em rede e transdisciplinaridade. Alínea, 2005. Disponível em: http://www.ia.ufrrj.br/ppgea/ conteudo/T1SF/Akiko/03.pdf. Acesso em: 3ago.2012.

. O dualismo perverso da escola pública brasileira: escola do conhecimento para os ricos, escola do acolhimento social para os pobres. Educ. Pesqui v. 38, no 1, p. 13-28. Edição on-line. 2012, Epub Oct 21, 2011. ISSN 15179702. Disponível em: http://dx.doi.org/10.1590/S151797022011005000001. Acesso em: 3ago.2012.

MALBERG, Carré de. Teoría General del Estado. 2. reimp. México: Facultad de Derecho/ UNAM; Fondo de Cultura Económica, 2001. Apud MARTINEZ, Vinício C. As calendas do Estado de Direito. In: Jus Navigandi, $\mathrm{n}^{\circ}$ 58. Edição on-line. Disponível em $<\mathrm{http}$ ://www1:jus.com. br/doutrina/texto.asp?id=3086>. Acesso em: 9 out.2002.

MAAR, Wolfgang Leo. O que é política. 16. ed. São Paulo: Brasiliense, 1994.

MARTINEZ, Vinício C. As calendas do Estado de Direito.

In: Jus Navigandi, $\mathrm{n}^{\circ}$ 58. Edição on-line. Disponível em $<$ http://www1:jus.com.br/doutrina/texto.asp?id=3086>. Acesso em: 9out.2002.

MONTESQUIEU, Charles-Louis de Secondat. Do espírito das leis. Tradução, introdução e notas de Edson Bini. Bauru: Edipro, 2004. (Série Clássicos)

MOREIRA, Herivelto; CALEFFE, Luiz Gonzaga. Metodologia da pesquisa para o professor pesquisador. 2. ed. Rio de Janeiro: Lamparina, 2008.

MÜLLER, Friedrich. Que grau de exclusão social ainda pode ser tolerado por um sistema democrático? In: Revista da Procuradoria Geral do Município de Porto Alegre. Porto Alegre: Secretaria Municipal de Cultura, 2000. Edição especial.
RIBEIRO, Renato Janine. A democracia. São Paulo: Publifolha, 2001.

SAVIANI, Dermeval. História das ideias pedagógicas no Brasil. 3. ed. rev. Campinas: Autores Associados, 2010.

SCHIMDT, Maria Auxiliadora. A formação do professor de história e o cotidiano da sala de aula. In: BITTENCOURT, Circe (Org.). O saber histórico na sala de aula. São Paulo: Contexto, 1997.

Construindo a relação conteúdo/método no ensino de história no Ensino Médio. In: KUENZER, Acácia Zeneida (Org.). Ensino Médio: construindo a proposta para os que vivem do trabalho. 3. ed. São Paulo: Cortez, 2002.

SILVA, Tomaz Tadeu da. Documentos de identidade: uma introdução às teorias do currículo. Belo Horizonte: Autêntica, 1999. 